\title{
Heterogeneidad y transculturación en El Gran Jaguar de Bernardo Valderrama Andrade
}

\author{
Carlos Bernal Granados ${ }^{1}$
}

\begin{abstract}
Resumen
La importancia de la heterogeneidad cultural y discursiva de los países de América Latina, se constituye en el marco teórico y en la herramienta fundamental para la comprensión de determinados fenómenos como la transculturación y como derivación de ésta, el problema de la identidad, alteridad y en especial el de la cultura popular. El presente trabajo aborda algunas de las principales modalidades de este influjo en la novela de El Gran Jaguar de Bernardo Valderrama Andrade, la cual surge como una propuesta y un reto a la literatura colombiana, mostrando, entre otros aspectos desde lo antropológico y cultural que el ser humano toma conciencia de su poder de destrucción con un profundo sentimiento de fracaso, desolación y abandono, y desde lo literario, la liberación de ataduras y la violación de normas estéticas caducas, creando un nuevo espacio donde cualquier época puede ser perfectamente contemporánea.
\end{abstract}

Palabras clave: cultura popular, heterogeneidad, hibridez, indigenismo, mestizaje, oralidad, transculturación. 


\title{
Heterogeneity and transculturation in El Gran Jaguar of Bernardo Valderrama Andrade
}

\begin{abstract}
The importance of the cultural and meditative heterogeneity of the Latin American Countries, has been established in the theoretical structure and in the fundamental tool for the comprehension of determined phenomenon such as the transculturation and as the derivation of this, the identity problem, the alteration, and specially the popular culture problem. The actual work approach some of the main modalities of this influx in the story of the El Gran Jaguar of Bernardo Valderrama Andrade, which story spring up as a proposal and a challenge to the Colombian literature, showing, between other aspects from the anthropologic and cultural, that the man is conscious of his immense destructive power with a deep failure sentiment, desolation and abandon, and from the literature, the liberation of bundles and the violation of expired aesthetic rules establishing new space where any epoch could be perfectly contemporaneous.
\end{abstract}

Keywords: Heterogeneity, mestizaje, hybridity, transculturation, orality and popular culture, indigenismo.

\section{Introducción}

A pesar del olvido y el desprecio que ha sufrido el indígena por parte del sector ilustrado, siempre ha transitado en nuestro continente una corriente popular integrada por manifestaciones como las leyendas, los mitos, los refranes y proverbios, las canciones, los relatos orales y las manifestaciones folklóricas en general, muchas de ellas expresadas en forma oral y en lenguas diferentes de las de origen europeo, y nutridas de tradiciones culturales indígenas o africanas.

En líneas generales la heterogeneidad de la que estamos hablando en el ámbito americano, es una heterogeneidad de profunda significación cultural que supera aquellas de orden regional, local, parroquial y nacional; también trasciende la de 
índole social, vertical u horizontal; es la que está arraigada en el área desde el mismo momento del encuentro (choque o desencuentro) cultural iniciado por el proceso histórico de descubrimiento y conquista de América.

Este hecho es fundamental para el presente trabajo, incluso es el instante crucial en que la novela, El Gran Jaguar, deja planteado como ficción al finalizar sus páginas, pero como realidad, es el anuncio de devastación y el inicio del proceso de transculturación.

Ahora bien, las concepciones homogeneizantes de los procesos literarios latinoamericanos han negado sistemáticamente, el rango de literariedad a las manifestaciones que no corresponden al modelo cultural dominante. Esta perspectiva manifiesta en la mayoría de las historias literarias, reduce el corpus de nuestra literatura a las obras escritas ya sea en español o portugués, las cuales responden a una serie de procedimientos estéticos y códigos que pertenecen a la llamada cultura ilustrada.

La interacción entre elementos y manifestaciones de esos dos espacios culturales igualmente válidos, es de doble vía: en la primera, las formas culturales populares dejan entrever transformaciones originadas bajo el influjo del ámbito ilustrado; en la segunda la presión de lo popular llega a alterar, subvertir y transgredir los modelos ilustrados dominantes.

Este último proceso cultural, que se hace evidente en numerosas obras de la narrativa latinoamericana, no ha sido sin embargo suficientemente explorado en la narrativa colombiana.

Heterogeneidad cultural, mestizaje, hibridez, transculturación, oralidad y cultura popular son categorías de primerísimo orden para el desarrollo del presente trabajo. Todas guardan relación directa ya sea a procesos culturales, históricos, raciales y que de alguna u otra manera, están en la base misma de las diferencias sociales, culturales y esencialmente literarias de la realidad latinoamericana.

El interés en la creación literaria de una voz popular, entronca de lleno con una dirección de creciente importancia dentro de la literatura latinoamericana contemporánea: todas comparten el interés en ascenso por la lengua hablada como el más autentico sostén de la literatura de ficción que ampara la incorporación literaria de un universo popular cuya existencia había sido hasta hace poco olvidada e incluso negada. Su presencia en el cuento y en la novela enriquece increíblemente la literatura latinoamericana, abriéndole de golpe nuevos cauces artísticos; al mismo tiempo que revela para siempre cómo nuestra cultura no concluye en las voces de esa burguesía más o menos autóctona (Julio Cortázar, Carlos Fuentes), más o menos europeizante o americanizada (Adolfo Bioy Casares, José Donoso), la cual ha dominado hasta ahora como personaje la literatura de intención realista en el continente. 
Voz popular que abarca la noción de autor como oído y recopilador de documentos, sosteniendo la elaboración de una literatura que expresa la mentalidad popular; literatura por lo tanto siempre abierta, pues las voces son infinitas y no nos importa de ellas una historia cerrada, sino su versión de la realidad y su contacto entre sí. Literatura que realiza la historia en cada uno de sus textos y nos obliga a confrontar el placer artístico con el contexto social e histórico. Si fuera ése en efecto el paradero por ejemplo de la literatura indigenista, según lo sugiere el caso de Colombia, donde la cuestión indígena siempre ha sido ignorada, podría por esa vía el complejo problema indígena, afirmar su vitalidad como objeto literario, aunque parezca ridículo hablar de literatura indígena colombiana mientras allá, en las selvas amazónicas, en los Llanos Orientales, en la Sierra Nevada de Santa Marta, en las montañas y ríos del departamento del Cauca y demás lugares, los descendientes de las diferentes culturas indígenas luchan en la actualidad por su supervivencia, tierra, seguridad, cultura e identidad.

Bernardo Valderrama Andrade presenta una visión general de las culturas indígenas de América. Esta visión se relaciona con la cosmovisión que presenta en El Gran Jaguar de los habitantes del país de la Montaña Blanca. Por ello, es importante adentrarse en el pasado de Colombia y de América Latina.

Desafortunadamente hay muchas lagunas en este terreno, en lo que toca con nuestro territorio. Las evidencias de los antiguos pueblos y culturas de Colombia sólo han podido esclarecerse parcialmente por las construcciones funerarias y uno que otro vestigio arquitectónico o escultórico. Pero gran parte de lo que fueron permanece bajo el polvo de la ignorancia o de la falta de investigaciones más serias y sistemáticas.

\section{Heterogeneidad discursiva en El Gran Jaguar}

Hay heterogeneidad discursiva porque existe heterogeneidad de mundo. Ahora bien, existe transculturación discursiva (literaria, narrativa) porque hay heterogeneidad de mundo. También existe heterogeneidad discursiva porque existen dinámicas de transculturación generadas por la heterogeneidad de mundo.

La dinamicidad origina tipos y grados de transculturación. Por ejemplo, los traslados o intercambios de objetos, tecnologías, usos y costumbres constituyen un tipo de transculturación que se puede denominar de materialidad tangible. A menudo las transferencias materiales suponen el uso de la fuerza y se vinculan con las otras dinámicas del contacto como son entre otras: el colonialismo, la explotación, etc. 
El intercambio de valores, concepciones, visiones y categorías, constituye uno de los grados de transculturación, el cual se desenvuelve y desarrolla en el ámbito filosófico. Desde el punto de vista literario, interesa particularmente el grado de transculturación que maneja signos, referentes y discursos, el cual pertenece al orden semiótico. Transferir imágenes del otro y producir interpretantes del otro es entrar en el grado mínimo de lo que se ha denominado, «transculturación semiótica» ${ }^{2}$.

Otros grados serían el intercambio de discursos no sólo de significados ${ }^{3}$, para hacer referencia a una transculturación que opera en el ámbito de los conquistadores españoles. Al respecto, Raúl Bueno al referirse a la categoría de la heterogeneidad y por ende al grado de la transculturación semiótica, expresa:

La heterogeneidad de que habla Cornejo Polar no es el mero contacto de culturas, ni la pluralidad conflictiva de mundo, o la totalidad contradictoria que él señala en otros lugares; ni el mestizaje cultural (o su isótopo, la hibridación), ni los procesos de transculturación: es el acto semiótico que surge de la heterogeneidad básica o de mundo y que implica la comprensión profunda y honesta de la cultura alternativa (Bueno, 1996: 45).

En grados más elaborados de transculturación semiótica, están los discursos que en el proceso de referencia a la heterogeneidad de mundo devienen heterogéneos ellos mismos. Ángel Rama (1982a) y Antonio Cornejo Polar (1996), los han estudiado a profundidad, a veces con coincidencia de objeto, como en el caso de la novelística de José María Argüedas.

El primero ha puesto el énfasis en la constitución misma del signo literario: ante las presiones literarias de la cultura burguesa capitalista y metropolitana, ciertas literaturas regionalistas, en su lucha por salvar estimables valores y contenidos culturales propios, se desprenden de sus formas tradicionales y dejan el espacio libre para el ingreso de formas vanguardistas y metropolitanas, a la vez que para formas más tradicionales y locales, que estaban relegadas incluso en su ámbito regional, para constituir una literatura transculturada y profundamente heterogénea. A este tipo de novela, Rama la ha llamado novela de la transculturación narrativa. En un caso equivalente, como es el de las crónicas, Cornejo Polar también ha dedicado especial atención a este tipo de heterogeneidad (o de transculturación) en que la forma discursiva se modifica por presiones exteriores, como del universo heterogéneo que representa ${ }^{4}$.

El segundo en cambio, ha puesto el énfasis en las referencias y a partir de ahí, en naturaleza dual -el doble estatuto socio-cultural- de las literaturas heterogéneas,

2. Expresión acuñada, fundamentada y trabajada por Antonio Cornejo Polar.

3. Por ejemplo los relatos del Génesis o la Pasión de Cristo.

4. Por ejemplo el significativo «Diálogo» de Cajamarca. 


\section{Carlos Bernal Granados}

Heterogeneidad y transculturación en El Gran Jaguar de Bernardo Valderrama Andrade. Artículo producto de la investigación.

las cuales son conjuntos discursivos que circulan en una cultura, pero que se refieren a otra, a la que tratan de revelar y entender.

Lo anterior significa que en la heterogeneidad cultural todo signo referente a la otra cultura entraña homológicamente la heterogeneidad de base. Así por ejemplo, se dice acerca de la literatura indigenista que siendo un conjunto discursivo que circula en una cultura, no obstante se refiere a otra de corte popular a la que trata de revelar y entender.

Por lo anterior consideramos importante tratar seguidamente y en primer lugar, la contextualización de la novela de Valderrama Andrade dentro del ámbito de la narrativa colombiana contemporánea; en segundo lugar resaltar algunos aspectos narrativos en ella. Sería motivo para otra investigación, el contexto histórico, político, social, económico, cultural y mítico-religioso de los habitantes de la Montaña Blanca, y la identificación de los elementos como indicadores de lo popular en El Gran Jaguar.

\section{El Gran Jaguary la narrativa colombiana contemporánea}

Ya es un lugar común afirmar que la narrativa colombiana actual está determinada por la obra de García Márquez: antes y después de Cien años de soledad (1967). Con la publicación de esta novela se instaura una nueva narrativa en la que el reino de la oralidad se superpone al de la escritura y construye un universo épico que está en íntima relación con las sociedades populares.

Luz Mery Giraldo ${ }^{5}$

La novela colombiana contemporánea desde la década de los setenta hasta la actualidad, permite hablar de formas narrativas que cuestionan los cánones establecidos por escritores de generaciones anteriores.

En efecto, llama la atención el alto número de autores y obras que logran romper el mito del puro macondismo y del realismo mágico, dando así una vitalidad a la narrativa que se expresa en su fuerza creativa con una abrumadora riqueza de temas, tendencias y estilos ${ }^{6}$.

5. Giraldo, L.M. 1994a. De cómo dar muerte al patriarca (Prólogo). En: L.M. Giraldo (comp.). La novela colombiana ante la crítica 1975-1990. Bogotá: CEJA, Universidad del Valle, p. p. 9-25.

6. No nos interesa mencionar toda una lista de escritores y obras. Es muy difícil para los historiadores y críticos de la literatura llegar a un acuerdo. La mención como las cifras exigen tanto una selección cualitativa como una estructuración según ciertos criterios. Si bien es cierto que se ha establecido un cierto consenso en cuanto a algunas obras reconocidas por la crítica, siguen siendo notables las diferencias de los estudios críticos sobre la historia de la novela de estas décadas y de fin de siglo, publicadas recientemente. Mencionamos las referencias que consideramos más importantes: Seymour Menton, La novela colombiana: planeta y satélites. Bogotá: Plaza \& Janés, 1978; J. Jaramillo Zuluaga, «Alta tra(d)ición de la narrativa colombiana de los ochenta». Boletín Cultural y Bibliográfico. Banco de la República. Bogotá, 1988, XXV, (15): 7183; César Valencia Solanilla, «La novela colombiana contemporánea en la modernidad literaria». En: Manual de Literatura colombiana. (Tomo II). Bogotá: Planeta, 1988, Pp. 463-510; Álvaro Pineda-Botero, Del mito a la posmodernidad. La novela colombiana de finales del siglo XX. Bogotá: Tercer Mundo Editores, 1990; Raymound Williams, Novela y poder en Colombia: 
Si después de García Márquez la novela empezaba a mostrar un carácter multifacético y heterogéneo, en la década del noventa, esos rasgos se extreman logrando una mayor radicalización en los proyectos narrativos y una profunda autoconciencia reflexiva de los escritores, cada uno con su personal preocupación novelística desde diversos factores culturales. Dichos factores se relacionan con el lenguaje, la historia y la ciudad. Cada uno de ellos corresponde a un proceso independiente e integrado que puede identificarse en una triple conquista: la de la conciencia histórica y del lenguaje como estructura y la del pensamiento citadino (Giraldo, 1991a: 8, 1994b: 9).

Para la narrativa colombiana el acceso a la mayoría de edad ha significado al mismo tiempo la adquisición de una mayor conciencia sobre sí misma y la conquista de la libertad (Valencia, 1976: 276). El narrador reconoce en la escritura un oficio que exige trabajo y el dominio de unas herramientas específicas, un oficio solitario y marginal, expresión de una individualidad que no puede por sí sola asumir la definición de una tradición y una realidad mucho mayor y compuesta por múltiples elementos.

La escritura se libera entonces de responsabilidades y presiones y puede ser espontánea; "«cada narrador escribe desde su propia esquina» y todos unidos producen una narrativa independiente, profesional, que se arriesga en variadas experimentaciones y juegos, que reconoce y recrea su entorno, que enfrenta tanto el pasado histórico como la fantasía, que se fascina con el fenómeno de la ciudad y que asume su propio mundo, tratando de entenderlo y expresarlo libremente.

La mayoría de edad representa para la narrativa colombiana contemporánea el desprendimiento de unos modelos establecidos y el encuentro con una voz más auténtica, que ya no tiene que delinear con cada palabra el perfil de una identidad cultural que debería definirnos. De este modo se hacen posibles la diversidad, la heterogeneidad, y el panorama narrativo se amplía enormemente, comenzando a conformar, si no una escuela narrativa, sí una buena base de la que salen algunos de los más importantes narradores contemporáneos.

En cuanto a la entrada definitiva en la modernidad, ésta trae para la narrativa colombiana la experimentación, la mezcla de géneros, la complejidad del mundo moderno, la ciudad, las experiencias intelectuales, la crisis de la existencia, los elementos tomados de la publicidad y los medios de comunicación, la autoconciencia narrativa, la renovación del lenguaje, la conciencia histórica y otras muchas nociones y prácticas que sitúan definitivamente a la narrativa colombiana en el camino de una literatura moderna, que surge con los grandes

1844-1987. Bogotá: Tercer Mundo, 1991; Luz Mery Giraldo B. (Coordinación y compilación). La novela colombiana ante la crítica 1975-1990. Bogotá: Centro Editorial Javeriano CEJA, 1994. Karl Kohut (editor). Literatura colombiana hoy. Imaginación y barbarie. Frankfurt-Madrid: Editorial Vervuert, 1994; R. H. Moreno-Durán «La narrativa colombiana ante el fin del milenio». Quimera. Bogotá, 1995, (131-132): 32-35; Luz Mery Giraldo, «Fin de siglo XX: por un nuevo lenguaje (1960-1996)». En: María Mercedes Jaramillo, et al. (Compil.). Literatura y cultura. Narrativa colombiana del siglo XX. Volumen II: Diseminación, cambios, desplazamientos. Bogotá: Ministerio de Cultura, 2000, Pp. 9-48. 
escritores de comienzos del siglo XX (Kafka, Joyce, Proust, etc.) y se continúa a través de la obra de narradores como Cortázar, Borges, García Márquez o Carpentier, que han abierto a la literatura una infinita red de posibilidades a la narrativa contemporánea (Torres, 1992).

Junto a lo anterior, también se intensifica el desarrollo de la crítica literaria que desde las universidades, las revistas, suplementos culturales de los periódicos y compilaciones, comenta y analiza lo más destacado de la producción narrativa.

En general, los críticos hablan de un recorrido de la narrativa colombiana durante estas dos últimas décadas, que va desde la imitación del realismo mágico, pasando por un revivir de la novela de denuncia y violencia, hasta una forma de narrar que se interesa por la vida cotidiana, se acerca a las historias individuales, se sitúa principalmente en el espacio urbano y se adentra en la realidad.

Una buena parte de los autores que publican en los años setenta y ochenta, hablan de la vida de las ciudades, la familia, los grupos sociales, los adolescentes, las ilusiones y desengaños de la alternativa revolucionaria, las contingencias políticas, las urgencias de los intelectuales, e incluso, la dificultad de escribir una novela. Paralelamente, algunos narradores se interesan por los temas históricos, que reconstruyen con rigurosidad e imaginación, mientras que otros se empeñan en la literatura de denuncia, planteando problemas y situaciones sociales que revelan una profunda desigualdad e injusticia y otros insisten sobre las fórmulas del macondismo, explorando permanentemente tradiciones e historias hasta encontrar los elementos mágicos que articulan la realidad.

La novela El Gran Jaguar por sus cualidades narrativas que veremos más adelante, se circunscribe de alguna $\mathrm{u}$ otra manera en varios de los aspectos mencionados dentro del panorama de la narrativa contemporánea colombiana y latinoamericana. Sin embargo, la crítica literaria no la ha explorado lo suficiente, quizás porque aún no se ha comprendido el valor que ésta pueda tener en el ámbito de las letras colombianas y latinoamericanas, entre otros aspectos para adentrarse en su valor artístico, cultural y antropológico. Prácticamente la ha desconocido. En consecuencia, veamos la escasa recepción crítica que ha tenido:

Los premios literarios no garantizan nada. Hay obras que los obtienen y en lugar de ser leídas caen en el olvido injustamente, porque a veces es tal el descrédito de ciertos concursos, que mejor sería no habérselos ganado, como ocurrió con El Gran Jaguar, la novela de Bernardo Valderrama Andrade, galardonada hace años por Plaza \& Janés y condenada, en consecuencia, a la indiferencia de los libreros, los lectores y hasta del propio editor «y de la crítica literaria» ${ }^{7}$. Y es una lástima, porque hoy, releída varios años después de la noticia, no sólo se defiende sino que permanece con los méritos que otorgan a una obra la posibilidad de jugar al ave fénix (Ramírez, 1997). 
De otra parte, Luz Mery Giraldo, también hace un llamado de este hecho, cuando expresa:

[...] nuevos discursos con diferentes y variadas propuestas, tanto en lo temático como en lo formal, permiten afirmar que existen narradores que dan y darán mucho de qué hablar, cuestionar y analizar. Narradores que están a la espera de ser leidos, estudiados, criticados y traducidos, que hacen tambalear las estructuras literarias convencionales, así como las mismas estructuras institucionalizadas. [...] Bastaria con evaluar los concursos literarios de cuento y novela en sus variadas calidades, para comprender que el género narrativo está en un intenso proceso de producción. [...] Al concurso nacional de novela Plaza \& Janés se enviaron cerca de 90 obras, dando como ganadora El Gran Jaguar de Bernardo Valderrama, sin ser registrado el hecho en ningún medio cultural. [...] Hablar de la narrativa de fin del siglo XX en Colombia significa proponer un cambio de perspectiva y abrir el horizonte de los autores a nuevas modalidades, que en muchos casos no tienen resonancia en nuestro lector convencional. Desde fines de los setenta y sobre todo durante la década inmediatamente pasada, se ha ido gestando una literatura francamente transgresora de los modelos establecidos. Este fenómeno empieza a ser tímidamente favorecido por la industria editorial (también en proceso de desarrollo), acompañada de una nueva actividad crítica, efectuada preferencialmente en los ambientes académicos (Giraldo, 1994: 14-15).

Precisamente, desde el ámbito académico, han surgido los contados comentarios, reseñas críticas y dos artículos publicados que dan cuenta de la obra. Veamos:

La primera reseña crítica que dio a conocer la obra por primera vez, fue publicada a los dos meses de haber salido al mercado (Giraldo, 1991b: 15). El crítico y jurado del concurso, Eduardo Pachón Padilla, incluye igualmente una reseña en la contraportada de la obra.

El primer estudio crítico que se ha escrito de la obra, también es de la autoría de Luz Mery Giraldo (Giraldo, 1992: 52-56). De igual manera, son varias sus alusiones críticas a la obra, ya imprescindible de dejar de mencionar en el ámbito intelectual de ahora en adelante en todo estudio serio de la narrativa colombiana, lo cual demuestra tímidamente que El Gran Jaguar hasta ahora, es motivo de interés para «ser leída, estudiada, criticada y traducida». Dichas alusiones, forman parte integral de los artículos que han sido publicados en diversos textos de crítica literaria, a propósito de la realización de foros, seminarios, congresos y encuentros sobre literatura colombiana y latinoamericana (Giraldo, 1991a, 1994a, 1994b, 1997, 2000). Otras alusiones a la obra las encontramos en Kohut, (1994); Pineda-Botero (1994). Este último se constituye en el segundo estudio crítico publicado sobre El Gran Jaguar. 
Como podemos observar, lo anterior contextualiza y proporciona a la obra de Bernardo Valderrama Andrade un lugar preferente en el panorama de la literatura colombiana y por extensión latinoamericana de fines del siglo XX.

Por el tratamiento que le otorga al indígena, por el excelente manejo temático, en tanto que recrea literariamente y reconstruye ficcionalmente el mundo prehistórico de los habitantes de Keka-Bunkua y en últimas por mostrar la razón de ser del indígena, en relación con el reconocimiento de una cosmogonía y cosmología particulares que permite acceder a esos mundos desconocidos y lejanos para el colombiano en los albores del siglo XXI, consideramos que su obra El Gran Jaguar se constituye en una propuesta indigenista ${ }^{8}$.

Propuesta que continuó afianzándose, ya que «mediante la investigación antropológica, la búsqueda de fuentes y la visita al espacio geográfico -del autor-, permitieron la recreación de determinadas culturas americanas próximas al Centro del Mundo: la Sierra Nevada de Santa Marta» en Los ojos del cielo (Valderrama, 1993).

Otro aspecto que se aborda es la problemática de la identidad, la cual está planteada en la novela desde el horizonte antropológico, estableciendo coherentemente una visión del hombre colombiano, en cuanto a su propia identidad cultural se refiere, y al puesto que debe ocupar en la historia y en la cultura universal. Veamos dos ejemplos:

Cuando la fatiga se apodera de sus músculos y siente desfogados los impulsos, enrumba otra vez la embarcación hacia la costa y la aldea Kashingui, de la cual y como una paradoja, su otro yo tampoco quisiera alejarse. Estos sentimientos encontrados, esta ambivalencia de su personalidad, unas veces lo identifica con su padre, $[. .$.$] y otras con su madre, desarraigada de su tierra y de su gente.$ El hallazgo de restos humanos y algunos utensilios, pertenecientes a su bagaje expedicionario, confirmó sus presunciones; los ubatashi se miraron entre sí: los recuerdos de sus compañeros surgieron como una evocación trágica y hasta al inconmovible Conoh se le enrojecieron los ojos: la inmensidad de su desventura, el peso de la soledad en estas tierras, la verdad de su mundo perdido tal vez para siempre... (Valderrama, 1991: 61; 81).

En resumen, toda esta gama de posibilidades se proyecta y hace que sea utilizada indistintamente por casi todos los escritores colombianos de finales del siglo $\mathrm{XX}$, entre ellos Bernardo Valderrama Andrade, pues su propuesta indigenista es un aporte al avance del desarrollo del género de la novela indigenista, en la literatura latinoamericana y colombiana por las razones ya anotadas. Igualmente, por el significativo interés de estudiar la heterogénea y compleja realidad cultural latinoamericana, y en particular la colombiana de los habitantes de la Montaña Blanca desde la literatura. Por fin, la literatura colombiana ha encontrado la forma exacta de expresarlo y de narrarlo. 
En cualquier caso que se asuma a partir de la novelística de Valderrama Andrade ya sea de corte: indianista; indigenista: «La novela es una novela indigenista, genuinamente regional y desarrollada en un período real» (Pachón, 1991); neoindigenista; histórico, urbano; «El interés de la novela está más que en la innovación o la experimen $\neg$ tación formal y temática, en la visión del mundo urbano, o en la reflexión analítica de la historia occidental y el proceso de la transculturación» (Giraldo, 1992: 52); epistemológico, de conocimiento, ideológico: «El Gran Jaguar de Bernardo Valderrama Andrade, es una novela de conocimiento o epistemológica, la cual construye un espacio para la indagación de las ideas, la cultura y la sociedad. En ella, sobresale lo ideológico frente a lo anecdótico y el lenguaje, sin descuidar ni lo uno, ni lo otro» (Giraldo, 1991a: 13) o heroico: « [...] es bien sabido que en la tradición literaria latinoamericana no ha existido propiamente el género épico [...] Se configuran pues dos universos, dos líneas de acción, dos visiones de mundo, y dos estilos literarios dentro de la misma obra y dentro de los mismos hechos: lo épico y lo novelesco. [...] A lo largo de la obra se presenta pues un hábil contrapunto entre epopeya y novela. El equilibrio permite leer lo épico desde la perspectiva del lector moderno que necesita una línea argumental. Los protagonistas están caracterizados para establecer cada uno de los dos géneros. Parecería que privase lo épico, pero se trata de una epicidad en trance de muerte [...] la novela presenta una visión totalizante de la cultura indígena dentro del panorama histórico de los últimos cinco siglos» (PinedaBotero, 1994). También que Bernardo Valderrama sea merecidamente tildado como «narrador de la transculturación» (Rama, 1982), o como contestatario del poder: «[...] la nueva narrativa latinoamericana comparte de país a país algunos rasgos como: intensa productividad, recuperación del realismo, descubrimiento y apropiación del espacio urbano, evolución modernizadora, retorno a la historia, interés por los sectores marginales y especialmente por su lenguaje particular y ampliación de la comunicación entre narrador y lector, entre otros. Destaca la labor de los novísimos narradores, que debieron superar el éxito de los modelos de la narrativa del boom y a partir de allí crear una narrativa propia, por eso los llama "contestatarios del poder"».

Sea lo que fuere, el presente trabajo desea constituirse en un abrebocas para el estudio y análisis de la novelística de Bernardo Valderrama Andrade y para que esta ocupe su merecido puesto como aporte al desarrollo de la literatura colombiana y universal.

\section{Narratividad en El Gran Jaguar}

Aquí se trata de ver occidente desde la comunidad y dejar de ver la comunidad con la óptica de occidente.

Guillermo Bonfil Batalla ${ }^{9}$ 
Heterogeneidad y transculturación en El Gran Jaguar de Bernardo Valderrama Andrade. Artículo producto de la investigación.

Desde el punto de vista argumental, Bernardo Valderrama propone una estructura circular y cerrada para recrear el mundo primigenio de los habitantes del país de la Montaña Blanca, destruido por la Conquista española. En otras palabras, cuando el círculo se cierra no comienza dialécticamente de nuevo su ciclo eterno de cada 152 solsticios, sino que se da inicio a otro proceso diferente con una visión distinta del mundo, del hombre y de los dioses.

En esta ocasión los festejos revisten significativa importancia y solemnidad, por su coincidencia con otro gran acontecimiento: la aparición periódica en los cielos nocturnos de kavi-Tama, la estrella del Gran Jaguar, presente cada ciento cincuenta y dos solsticios, hecho que determina cambios decisivos en el rumbo de la nación.

[...] Según se ha corrido la voz por toda la Sierra Nevada, con motivo de la visita de la estrella del Gran jaguar, el sacerdote mayor hará trascendentales revelaciones...

La satisfacción reflejada en su rostro, una constante desde las victorias logradas sobre los invasores de Keka-Bunkua, esa noche, de pronto, se desdibujó cuando depositó las cuentas de cristal de roca en el recipiente de cerámica... iNo podía ser! De nuevo, en la interpretación de las burbujas, vio hombres rubios amenazando el futuro de las gentes de la Montaña Blanca... Tiene los ojos desorbitados y las pupilas afiebradas; se muerde los labios hasta sangrar. ¡No puede ser!... Pero ahí están: ;Otra vez marcados en el firmamento!: son un tropel. (Valderrama, 1991: 47; 48; 226).

Puente que se rompe entre nuestra prehistoria y la historia de Occidente dejando un vacío congelado. Inicio del proceso de aculturación.

...Ya en el fondo, en un espacio abierto en forma parcial, la escena era prodigiosa y épica: de pie en mitad de la gruta, a donde todavía llegaba la claridad del exterior, también congelados, uno frente al otro, estaban Senoname-maku y Ubatashi-thor con las lanzas de macana en alto, apuntándose; en la mirada, la última expresión con la cual se midieron antes que Monsaui, Dueño de la Nieve, se apoderara de ellos....

...la entrada la obstaculizaba un enorme cóndor congelado, de espaldas al exterior, ...aún con sus potentes alas desplegadas. Bajo la piel de hielo que lo cubría, parecía conservar la vida... como si apenas estuviera atrapado en forma temporal... (Valderrama, 1991: 225).

Estos textos muestran claramente la estructura cíclica de la obra y la maestría narrativa con que el autor la evidencia, alternándola con sus personajes legendarios y míticos, con los sacerdotes y las sacerdotisas. Con sus mitos y creencias, con los guerreros y sus mujeres, «con la religión, gobierno, régimen matrimonial, costumbres, usos, oficios, adiestramiento militar, alimentación y 
demás modos de vivir». Con la naturaleza, el paisaje y con todos los habitantes del país de los Tairona con sus alegrías, tristezas, sentimientos, pasiones y temores. Todo ello,

...dentro de una acción a veces apacible en torno a las actividades de sus dirigentes, como astrólogos y urbanistas, en otras alternando la mayoría al recrearse en simples reuniones hogareñas, en diversas festividades comunes, en rigurosas ceremonias solemnes, o en aquellas completamente activas, plenas de riesgos, inherentes al furor de contiendas bélicas. Está formada por un esplendoroso paisaje, compuesto de serranías, mesetas, mar, ríos, floresta, sembradios, fauna, sol, luna, poblados; y de un escenario interior, integrado por exclusivos recintos para la oración y la reflexión de sus sabios sacerdotes, de cabañas en donde las mujeres se dedican a la crianza de sus hijos y a las labores manuales, y de campamentos en los cuales los hombres se ejercitan en maniobras guerreras... (Pachón, 1991).

La obra se inicia con un mapa de los Taironas de 1378, D.C. y narra la historia en 33 capítulos que al presentarlos alternadamente, le otorgan movimiento y simultaneidad a los sucesos. Luego se presenta al lector una serie de notas aclaratorias, de orden histórico y ficcional, acerca del origen de las tribus invasoras, y sobre todo el concepto y sentido que el autor adopta y maneja en la novela para designar a la cultura Tairona de «país de los tairona» o «país de la Montaña Blanca», que no debe «tomarse con los mismos elementos de comparación de nuestra perspectiva occidental». Aclara la utilización de vocablos indígenas utilizados en la novela como de los Tairona pero que en realidad son de los Kogi; luego presenta un índice de personajes que ubica al lector en el manejo de los diferentes roles y relaciones entre los actantes. Finalmente, 612 años después, la obra cierra su círculo con otro mapa de 1990 del país de la Montaña Blanca pero mostrando las zonas arqueológicas de lo que quedó después del proceso de transculturación.

El Gran Jaguar se desenvuelve entre la defensa de las tierras y la lucha por la convivencia pacífica de los habitantes de la Montaña Blanca con los pueblos invasores.

Antes de 1492, los pueblos invasores son de dos clases: los caribe y los ubatashi que en distintos momentos llegaron a la Sierra Nevada por el mar, unos con el ánimo de establecerse en la región (los kashingui de la tribu caribe y los ubatashi) y otros, con el deseo vehemente de conquistar y de apoderarse de los territorios de los Tairona (los gulamena y los sangaramena también de la tribu de los caribe).

Según los relatos de los Kogi, en los «tiempos míticos» arribó a las costas de la Vertiente Norte, en inmediaciones de la desembocadura del Hukumeiji-Tukue (hoy río Palomino), la «gente de los ojos azules», llamados ubatashi (de $u b a$ 
= ojo; y tashi $=$ azul o verde), con los cuales se libró una guerra de exterminio (Valderrama, 1991: 229) ${ }^{10}$. Al respecto afirma Pineda-Botero, que «la presencia de esta segunda categoría de invasores prefigura grandes catástrofes y sugiere una posibilidad que ha sido planteada en otros medios. Los vikingos habrían llegado a América en un tiempo mitológico. Aunque no dejaron asentamientos, sí aparecen huellas de su existencia en las tradiciones orales de los indígenas actuales, los Kogi» (Pineda-Botero, 1994: 80) ${ }^{11}$.

Las batallas y las guerras; las relaciones amistosas y no amistosas, y las relaciones de pareja que se establecieron entre los habitantes de la Montaña Blanca con este primer grupo de invasores, se dio dentro del mismo contexto en referencia a iguales y equitativas condiciones, necesidades y realidades desde el punto de vista espiritual y material, solamente con algunas diferencias de orden organizacional desde lo político, social, cultural, mítico y religioso. Por ejemplo, en la guerra se daba un equilibrio e igualdad de ocasiones ya que nunca se atacaba a un contrincante en forma de no darle oportunidad de defenderse. Los otros invasores, los españoles, eran de otra condición y con unos intereses e ideales muy diferentes.

En la novela, se presentan dos estilos: lo épico y lo novelesco, los cuales se alternan indistintamente en cada uno de los capítulos para presentar y contar las acciones de los personajes heroicos o no, que en cierta forma configuraron el pasado legendario y decidieron el destino de los habitantes del país de los Tairona. En consecuencia, «la voz narrativa, asumiendo una posición de una supra-perspectiva omnisciente ${ }^{12}$, propia del género épico, va pasando de tribu en tribu para describir los preparativos y motivaciones de cada una» (PinedaBotero, 1994: 81), bajo la diversidad de temas, la vastedad del espacio y el tiempo. Igualmente esta voz narrativa identifica perfectamente a los personajes que se constituyen en héroes y antihéroes.

Arranca del conocimiento antropológico de la región y del conocimiento intuitivo de la cultura, y lo visualiza con la voz de un juglar que regresa al tiempo primordial para revitalizarlo, al ponerlo en acción y contar desde la hazaña guerrera, la aventura amorosa, los rituales sagrados, la vida cotidiana, hasta las angustiosas premoniciones que revelan los astros. El narrador penetra en lo más profundo del cosmos. Entra y sale de los personajes, recorre experiencias individuales y colectivas y conduce al lector-espectador, al reino de El Gran Jaguar o la estrella que aparece cada 152 solsticios (Giraldo, 1992: 54).

10. El origen de estos visitantes no se conoce, por lo tanto, es de libre interpretación en la novela por parte del autor.

11. Es posible que por la ascendencia nórdica (alemana) del autor y por su amor por la cultura de los Tairona (Colombia), hiciera mención a la mitología vikinga.

12. Se trata de un narrador heterodiegético extradiegético quien en algunas ocasiones deja la narración en boca de los mismos protagonistas para contar algunos estados de conciencia. En estas oportunidades se trataría de homodiegésis intradiegética (citado por Pineda Botero, 1994). 
Ahora bien, la voz narrativa se constituye en intermediaria entre una cultura moribunda y el tiempo presente y a medida que va narrando intercaladamente los capítulos, esa voz anónima, progresivamente se va descubriendo y mimetizando en el personaje de Ulaban y éste a su vez, en la persona del autor.

Satisfecho con su acierto y observador por naturaleza, Ulaban permaneció en el caserio de Buritica el tiempo suficiente para detallar el desarrollo cultural de aquellas gentes. ...A Ulaban, desde el primer momento, lo movió el afán de investigar sobre el País de la Montaña Blanca: se aplicó a estudiar y entender a los taironas, y entre más los conocía, mayor fue su entusiasmo por la ordenada conducta social que los regía (Valderrama, 1991: 64; 65).

Desde el punto de vista del lenguaje, observamos que tiene un tratamiento estético. También el manejo e intensidad lírica, permite el conocimiento vital, poético y objetivo de la cultura tairona sin desconocer una visión del hombre, del mundo y de sus divinidades.

Ahora tienen sobre sus cabezas la luminosidad del cielo, acentuada en la ancha franja de la Avenida de la Luz; su brillo, en apariencia cercano, baña de suave claridad las cimas de Keka-Bunkua, destaca fantasmales sus picos blancos. A partir de ellos y en dirección al mar, los filos de las diferentes vertientes son majestuosas cascadas negras, salpicadas aquí y allá con el parpadeo de muchos puntos luminosos, como si las estrellas fugaces luego de sus raudos desplazamientos, se apagaran, cayeran y luego tomaran a encenderse, ya incrustadas e inmóviles entre los recovecos, laderas y cañones de la Montaña Blanca (Valderrama, 1991: 108).

Otro aspecto importante es que «con la reelaboración del mito y la leyenda, el autor hace vigente la oralidad y su sentido a través de la escritura, pues ésta preserva de la disolución de la memoria».

En particular, notamos en la obra objeto de estudio la utilización frecuente de vocablos indígenas propios de la lengua de los Kogi y que la novela asume ficcionalmente como de los Tairona, contribuyen a situarla en su marco real y presente, haciéndonos oír en contados diálogos a los personajes en sus particulares expresiones y sobre todo a la voz narrativa, traduciendo en todo momento, sobre todo en los primeros capítulos, los diferentes términos utilizados.

La marcha es lenta, sin prisa, recreados con la explosiva vitalidad de la vegetación, incentivo al calor que abrasa sus corazones y hormiguea con estímulos de delicia por toda la piel. Cuando ven al Kauxau, bejuco ojo de venado, de bellas flores rojas, estrechando y queriendo asfixiar el tronco de taiji, el guayacán, ellos a su vez se contagian, se enlazan, se acarician, 
se descubren secretos del cuerpo y se olvidan en el tiempo... -iNagluñi, Ula Yang!... iTe quiero! (Valderrama, 1991: 23).

Al parecer, esto logra en el lector moderno, una mayor credibilidad en la narración de las historias, sobre todo las del amor humano.

En el choque entre las dos culturas, entre los dos temperamentos, las dos visiones, las dos maneras de vivir y de sentir, se encarna el máximo elemento material con que trabaja la literatura. Y ello a partir del instante en que el escritor debe elegir la única lengua posible (que es la suya) para exhibir ese mismo choque llevado hasta sus últimas consecuencias. Queda como compensación y como prueba de la búsqueda y de sus hallazgos, la imagen de ese incierto equilibrio conseguido a través de la introducción de vocablos así no sean los propios de la cultura que esté tratando y utilice los de otra (Kogi) por obvias razones.

No obstante, expresa uno de los críticos de la obra, que:

Frente a tal vocabulario aparecen otros conceptos como «subconsciente», "concientizar», «mirada introspectiva», "hábitat», "sistema de gobierno justo y progresista», "teoría de las relaciones humanas», "nombres consagrados para la historia», que sin duda falsifican la pureza de lo tairona y que pertenecen a la jerga cientifica de nuestro siglo y a la visión del autor. La jerga indigena le da verosimilitud; la cientifica atenta contra tal verosimilitud pero acerca la obra al lector de nuestros días (PinedaBotero, 1994: 83).

Bernardo Valderrama centra el interés de la novela en la visión del mundo primigenio y de su cultura, en la reflexión analítica de la historia occidental y el proceso de transculturación. En otras palabras, la devastación está dada. Han pasado varios siglos de transculturación y de violencia oficiada en aras de la preservación e imposición de varios principios y valores normativos. «De ahí que cada personaje, ideología y comportamiento que amenacen la estabilidad y las normas deben cuestionarse recriminatoriamente, con violencia, despojo y condena, si es necesario», así sean tribus invasoras como los caribes y Ubatashis:

-No has aprendido -le grita- otra cosa distinta a violar, saquear, incendiar y matar; en consecuencia, como retribución, recibirás lo mismo. Y le añade con tono profético: -Actuando así nuestra gente nunca va a encontrar un espacio acogedor bajo el cielo de la Montaña Blanca. Estos territorios ya tienen dueño: son de gentes organizadas, poderosas, de cultura superior; dispuestas a defenderse; y quizás a compartir, si se desiste de la guerra... (Valderrama, 1991: 199).

Este hecho, en relación con el proceso de transculturación y pillaje, se puede entender también como la violación de la tierra madre y de la mujer. 
En consecuencia, el tratamiento del tiempo histórico en la novela, es nuestra prehistoria como evocación de la experiencia primitiva, anterior a la conciencia histórica. Al proponer el autor el reingreso a los orígenes; es decir, a la historia que contaron los primeros padres, aprovecha y utiliza mitos y leyendas propios de los indígenas, reinventando la historia y creando ficciones novelescas sobre la cultura indígena.

La novelística de Bernardo Valderrama Andrade surge como una propuesta y un reto a la literatura colombiana de comienzos de siglo. Por ejemplo, desde el punto de vista antropológico y literario, se observa por un lado, en la historia de la humanidad, que por primera vez el hombre es consciente de su inmenso poder destructivo con un profundo sentimiento de fracaso, desolación y abandono. Por otro, el novelista expresa la liberación de ataduras y la violación de normas estéticas caducas, creando un nuevo espacio donde cualquier época puede ser perfectamente contemporánea. En últimas se impone cada vez más una perspectiva sobre nuestro pasado cultural que busca colocar al hombre a la altura de su verdadera dimensión.

Lo anterior puede justificar de alguna manera, la afirmación de que El Gran Jaguar es una obra genuinamente indigenista en la literatura colombiana, la cual aparece en este mundo contemporáneo abocado en el espacio deshumanizado de la civilización occidental, conmoviendo, sensibilizando al lector-espectador en la añoranza de esos vínculos felices con la naturaleza y el pasado cosmogónico, e infundiéndole una conciencia clara de su situación actual frente a este mundo violento y tecnologizado. En otras palabras, «es el estado primigenio donde se dan cita los primeros tiempos y los tiempos contemporáneos».

Y por una asociación, explicable tal vez en el concepto de lejanía, los distantes picos iluminados le traen el recuerdo de Nyuba-Aluna, a quien teme haber perdido. ... Ulaban, de rodillas, levanta el rostro incrédulo; alcanza a distinguir en la incipiente noche, contra un fondo lejano de estrellas, la hermosa figura de su amada con los atavios de oro cubriéndole la piel de bronce. Y se extasía en admirarla, con los párpados cerrados, no distante y ceremoniosa, sino con un aire placentero, transformado por la determinación que la ha llevado hasta allí....En aquellos parajes solitarios donde el peligro parece lejano, sienten la tentación de tenderse en el suelo, a descansar las fatigas, y contemplar sin prevenciones la inmensidad de los contornos (Valderrama, 1991: 148; 149; 150; 169).

Finalmente, El Gran Jaguar de una parte, exige un lector culto, el cual como espectador, es necesario que tenga en cuenta dos ejes de participación cognoscitiva: el primer eje es de orden diacrónico o transversal, el cual es una línea escritural que una vez develada lo conecta con un pasado primordial desde el presente del tiempo de la lectura. El segundo eje, sincrónico, conecta las estructuras verbales del enunciado a una inteligencia, por parte del receptor, de 


\section{Carlos Bernal Granados}

Heterogeneidad y transculturación en El Gran Jaguar de Bernardo Valderrama Andrade. Artículo producto de la investigación.

los fenómenos socioculturales de la época, entendiendo que tales fenómenos, dentro del instrumental narrativo se dan como discurso estético, y no como meras formas no artísticamente elaboradas de denuncia, compromiso político, injusticia social, aunque estas sean objeto también de análisis como apropiación de la cultura popular. De otra parte, debe crear en el lector, un proceso de búsqueda de la naturaleza y de la bondad perdidas y hacia el porvenir, por la extinción de «las viejas costumbres viciadas» del presente.

\section{Referencias bibliográficas}

Bonfil, G. 1989. México Profundo. Una civilización negada. México, D. F.: Editorial Grijalbo, S. A.

Bueno, R. 1996. Sobre heterogeneidad literaria y cultural de América Latina, Memorias Congreso Internacional de Teoría, Crítica e Historiografía Literaria Latinoamericana. Puebla: Universidad de las Américas.

Cornejo A. 1996. El indigenismo y las literaturas heterogéneas: su doble estatuto sociocultural. En: Lectura critica de la literatura americana. Actualidades fundacionales, tomo IV. Caracas: Biblioteca Ayacucho, p. p. 451-468.

Giraldo, L.M. 2000. Fin de siglo XX: por un nuevo lenguaje (1960-1996). En: M.M. Jaramillo, B. Osorio, A.I. Robledo (Compil.). Literatura y cultura. Narrativa colombiana del siglo XX. Volumen II: Diseminación, cambios, desplazamientos. Bogotá: Ministerio de Cultura.

Giraldo, L. 1997. Fin de milenio y escritura del vacio En: K. Kohut (coord.). La invención del pasado. La novela histórica en el marco de la posmodernidad. Pp. 43-50. FrankfurtMadrid: Iberoamericana.

Giraldo, L. 1994a. De cómo dar muerte al patriarca (Prólogo). En: L.M. Giraldo (comp.). La novela colombiana ante la crítica 1975-1990, Pp. 9-25. Bogotá: CEJA, Universidad del Valle.

Giraldo, L. 1994b. La máscara y el espejo: la marginalidad y el arte. Texto y Contexto. 23: 89-90.

Giraldo, L. 1992. El Gran Jaguar. Memoria precolombina y anuncio de devastación. Universitas Humanistica. 35: 52-56.

Giraldo, L. 1991a. La novela colombiana de fin de siglo. Calidoscopio de una narrativa. Universitas Humanística. 34: 8-15.

Giraldo, L. 1991b. Gesta precolombina. "El gran jaguar», en el mercado la obra indigenista de Bernardo Valderrama, ganadora del Premio de Plaza y Janés. El Tiempo. Lecturas Dominicales, agosto 18. 
Kohut, K. 1994. Imaginación contra barbarie. (Introducción). En: Literatura colombiana hoy. Imaginación y barbarie. Frankfurt-Madrid: Editorial Vervuert, p. p. 9-24.

Pachón, E. 1991. «El gran jaguar» novela ganadora en el VII Concurso Nacional de novela Plaza y Janés, 1991. En: El gran jaguar. Bogotá: Plaza y Janés.

Pineda, A. 1994. La novela heroica en Colombia ante los quinientos años del descubrimiento. En: K. Kohut (ed.). Literatura colombiana hoy. Imaginación y barbarie. Frankfurt-Madrid: Editorial Vervuert, p.p. 73-83.

Rama, A. 1984. La ciudad letrada, Hanover: Ediciones del Norte.

Rama, A. 1982. Los procesos de transculturación en la narrativa latinoamericana en: La novela latinoamericana: 1920-1980, Bogotá: Procultura.

Rama, A. 1982a. Transculturación narrativa en América Latina, México D. F.: Editorial Siglo XXI.

Rama, A. 1982b. Los contestatarios del poder En: La novela latinoamericana 1920-1980. Bogotá: Procultura, p.p. 455-494.

Rama, A. 1975. Selección y Prólogo de Ángel Rama. En: José María Argüedas. Formación de una cultura nacional indoamericana. México, D.F.: Siglo XXI Editores, p. p. IX-XXIV.

Ramírez, I. 1997. Ave Fénix. El Tiempo. Lecturas Dominicales. (Sección Literalúdica). Bogotá, 16 de febrero.

Torres, P. 1992. Novela de los años setenta y ochenta En: Gran Enciclopedia de Colombia Temática: Literatura 4. Bogotá: Círculo de Lectores, p.p. 293-302

Valencia, H. 1976. La mayoría de edad. En: J.E. Ruíz, J.G. Cobo Borda, (Compil.). Ensayistas colombianos del siglo XX. Bogotá: Colcultura, p. p. 279-294.

Valderrama, B. 1993. Los ojos del cielo. Bogotá: Plaza y Janés.

Valderrama, B. 1991. El gran jaguar. Bogotá: Plaza y Janés. 